University of Texas Rio Grande Valley

ScholarWorks @ UTRGV

\title{
Effectiveness of Practicum Supervision as Perceived by Hispanic Undergraduate Rehabilitation Services Students
}

\author{
Roy K. Chen \\ The University of Texas Rio Grande Valley \\ Kim L. Nguyen-Finn \\ The University of Texas Rio Grande Valley \\ Jinhee Park
}

Follow this and additional works at: https://scholarworks.utrgv.edu/rhc_fac

Part of the Rehabilitation and Therapy Commons

\section{Recommended Citation}

Chen, Roy K., Kim L. Nguyen-Finn, and Jinhee Park. 2018. "Effectiveness of Practicum Supervision as Perceived by Hispanic Undergraduate Rehabilitation Services Students." Journal of Applied Rehabilitation Counseling 49 (4): 14-20. https://doi.org/10.1891/0047-2220.49.4.14.

This Article is brought to you for free and open access by the College of Health Professions at ScholarWorks @ UTRGV. It has been accepted for inclusion in School of Rehabilitation Services \& Counseling Faculty Publications and Presentations by an authorized administrator of ScholarWorks @ UTRGV. For more information, please contact justin.white@utrgv.edu,william.flores01@utrgv.edu. 


\section{Journal}

\section{of Applied}

\section{Rehabilitation}

$\cup$

Counseling

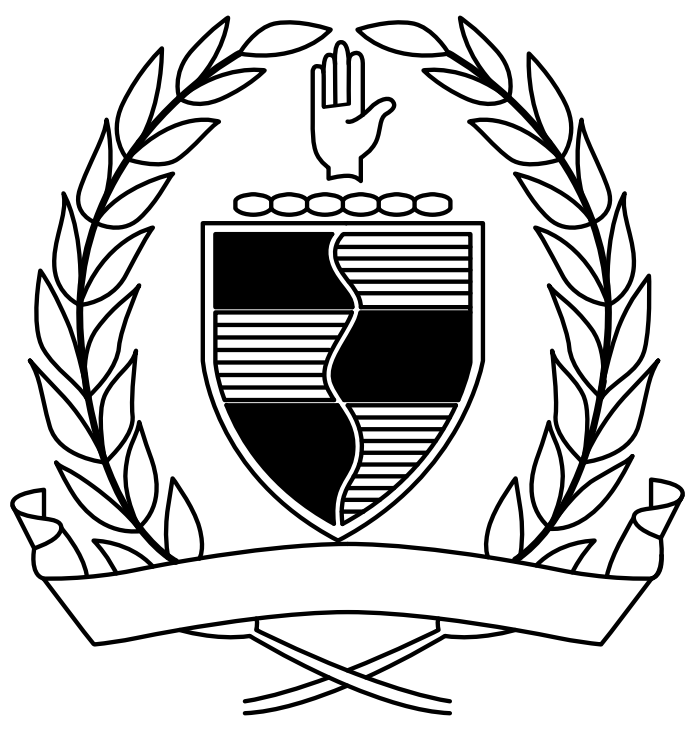

National Rehabilitation Counseling Association Volume 49, Number 4

Winter, 2018 


\title{
Effectiveness of Practicum Supervision as Perceived by Hispanic Undergraduate Rehabilitation Services Students
}

\author{
Roy K. Chen \\ Kim L. Nguyen-Finn \\ Jinhee Park
}

\begin{abstract}
Practica are integral to the culmination of systematic learning in higher education, particularly in fields such as health sciences and human services. For undergraduate rehabilitation services students, these placements typically mark the first-time students apply textbook knowledge to real life situations. Therefore, effective site supervision is an important part of the undergraduate field experience. The purpose of the present study was to examine the perceived effectiveness of undergraduate rehabilitation services practicum site supervision. The sample consisted of 154 Hispanic undergraduate rehabilitation services students. The findings show that students were satisfied with the supervision they received. Students also rated the competency of their site supervisors to provide effective supervision as high. Suggestions for future research, and implications for rehabilitation services educators and site supervisors are discussed.
\end{abstract}

Keywords: practicum supervision; undergraduate rehabilitation education; effectiveness of supervision

\section{Effectiveness of Practicum Site Supervision as Perceived by Hispanic Undergraduate Rehabilitation Services Students}

Practicum is a critical component in counseling and related educational fields. Practicum can provide students with realistic job experiences before they graduate and an opportunity to learn and practice counseling and other professional skills in the community (Bailey, Barber, \& Nelson, 2017). As stipulated in the Council on Rehabilitation Education (CORE) accreditation standards B.2.3 and C.5.11 (CORE, 2017), pre-service students must meet practicum and internship requirements under close supervision of faculty and site supervisors. The emphasis on such critical student learning outcomes was reinforced by the Council for Accreditation of Counseling and Related Educational Programs (CACREP), as it began assuming responsibility for the accreditation review process of graduate-level rehabilitation counseling programs in July 2017, after the merger of CACREP and CORE (CACREP, 2017a). According to CACREP (CACREP, 2015), students can apply theory into practice and develop counseling skills through supervised practicum experiences. Such practicum experiences also provide students with opportunities to counsel those of culturally and demographically diverse backgrounds.
Students enrolled in a CACREP-accredited program must participate in practicum under the supervision of both a faculty member and site supervisor to enhance awareness, skills, and knowledge in helping those from diverse populations (CACREP, 2015). As of the 2017-2018 academic year, 18 undergraduate programs in 14 states nationwide were recognized by CORE via the Registry of Undergraduate Rehabilitation Programs (CACREP, 2017b). Although not yet accredited by CACREP, undergraduate rehabilitation and other health-related programs educate and train students to prepare for careers as professionals in those areas (M. G. Brodwin, personal communication, September 9, 2018; M. Chapin, personal communication, September 10, 2018; R. F. Feroz, personal communication, September 9, 2018; B. C. Jenkins, September 9, 2018; F. Mercado, personal communication, September 14, 2018; J. Park, personal communication, September 10, 2018; K. B. Wilson, personal communication, September 9, 2018.).

Since practicum is one way to evaluate students' ability to work effectively with consumers in their chosen community setting, counseling and related education programs need to ensure that students receive quality pre-training and practical experiences under the proper supervision of faculty and on-site supervisors (Bradley \& Fiorini, 1999). Supervision is recognized as essential 
to professional development throughout the counselor's career as it plays a primary role in increasing competency (Herbert, Barrett, Evenson, \& Jacob, 2010; Schultz, Ososkie, Fried, Nelson, \& Bardos, 2002). To ensure that the quality of practicum site supervision is meaningful and effective, it is important to understand how students perceive their practicum supervision experiences.

\section{Importance of Practicum Experiences}

Practica are commonly understood as program-related work experiences within the community under the supervision of helping professionals (Hernandez, Bejarano, Reyes, Chavez, \& Mata, 2014). Practica present students with an opportunity to work with consumers and augment their knowledge of how to provide effective rehabilitation and mental health services (McCarthy, 2016; McElwee, O’Reilly, \& McKenna, 2002). They are typically the first opportunity given to students to apply theoretical knowledge in a real professional setting (Trepal, Bailie, \& Leeth, 2010). Students not only learn how to apply theoretical concepts into practice through practicum training experiences, but also explore whether such a career option could be the best fit for them (McCarthy, 2016; Mpofu, 2004; Trepal et al., 2010). Field-based experiences enable students to develop professional networks and enhance their career prospects (Hernandez et al., 2014; Trepal et al., 2010). It is understood that students gain most of their knowledge and skills through practicum; therefore, it is one of the most significant parts in their education (Daresh, 1990; Ryan, Toohey, \& Hughes, 1996; Trepal et al., 2010). Fernald et al. (1982) list seven responsibilities of site supervisors for undergraduate practicum students in the psychology and health and human services fields: (1) assist in developing the job description of the practicum student, (2) ensure that the student is a good fit for the agency, (3) provide training to the practicum student, (4) assist student in integrating into the agency, (5) conduct "regular, meaningful supervision sessions" (p.159), (6) document the supervision and training of the student, and (7) provide summative evaluation of the student at the end of the semester.

Students who completed a practicum or internship also tended to experience a smoother transition from college to work after graduation, better adjustment to work environments, more career development, and greater job satisfaction than those who did not complete a practicum or internship (Crebert, Bates, Bell, Patrick, \& Cragnolini, 2004; D’Abate, 2010; Shoenfelt, Kottke, \& Stone, 2012). Shoenfelt et al. (2012) stated that not only could undergraduate students benefit from quality practicum experiences by having a smoother transition from college to the workforce, but the real-world practical experience can help recent graduates be more competitive for employment with those who possess more advanced educational degrees.

\section{Practicum Supervision}

To maximize the results of practicum experiences, appropriate supervision is a necessary component in undergraduate education. Supervision is a process by which a more senior professional supervises a junior professional and evaluates how well the supervisee provides services to clients with the goal of increasing the supervisee's competency and assuring client welfare (Bernard \&
Goodyear, 2014; Glosoff \& Matrone, 2010). As mandated by CACREP (2015), students who are in a CACREP-accredited program should receive weekly individual and/or group supervision throughout their practicum and internship experiences (Section 3. H). Researchers have also asserted that clinical supervision during students' practicum and internship is crucial to the training and education of pre-service counselors and other helping professionals (Kuo, Connor, Landon, \& Chen, 2016; Trepal et al., 2010).

Practicum experiences can arouse feelings of both excitement and anxiety. Students may worry about their performance during practicum due to lack of self-awareness and limited understanding of theories and techniques (Jordan \& Kelly, 2011). They could feel overwhelmed when the demands of practicum are challenging, which may result in lowered confidence (Lynch, 1995). Supervisors, therefore, are crucial in reducing such distress, as well as increasing professional competency. Blanton (2001) postulated that practicum supervision experiences for undergraduate students should be geared toward increasing supervisee self-awareness, clarifying their values, integrating such values with their interventions, and establishing plans for their future career. Researchers have found that students who receive effective supervision based on structured feedback under supportive and encouraging environments will experience more positive professional growth (Lynch, 1995; McCarthy, 2016; McElwee et al., 2002; Trepal et al., 2010). Previous literature confirms that effective clinical supervision is significantly related to counselor satisfaction (Pitt, 2009), enhanced self-efficacy and confidence (Cashwell \& Dooley, 2001), and positive client intervention outcomes (McCarthy, 2013).

A study from Cheon, Blumer, Shih, Murphy, and Sato (2008) showed that supervisees in marriage and family therapy education programs were more satisfied with supervision when they perceived a stronger working alliance with their supervisor. Ladany, Ellis, and Friedlander (1999) also showed that practicum and internship trainees in counseling education programs who developed positive emotional bonds reported more satisfaction with their supervision experiences than their counterparts who did not develop positive emotional bonds with their site supervisors. Specific to rehabilitation service providers, McCarthy (2013) examined the relationship between supervisory working alliance and successful client vocational rehabilitation outcomes. The results of her study indicated that for novice counselors, the supervisory working alliance significantly predicted the number of successful case closures within the public vocational rehabilitation agencies.

A number of studies have paid attention to the effects of supervisors' contextual variables such as race/ethnicity, age, and sex and the similarity of such variables between supervisors and supervisees on supervision. Cheon et al. (2008) found in their study that matched supervisor and supervisee contextual variables (i.e., age, sex, ethnicity, sexual orientation, and religious/spiritual preference) did not influence supervisees' perceived satisfaction of supervision. Gatmon et al.'s (2001) study found similar results, indicating that although supervisees reported more satisfaction with supervision when their supervisors openly discussed multicultural issues during supervision sessions, the supervisorsupervisee match on cultural variables was not significantly 
related to supervisees' satisfaction with supervision. Jordan (2007) reported that supervisor behaviors and overall supervisory experiences were perceived as more important than supervisorsupervisee sex matches.

The topic of clinical supervision has been well addressed in the rehabilitation counseling field. However, the predominant focus of research was mostly on pre-service counselors in master-level rehabilitation counseling programs and/or in-service counselors in vocational rehabilitation settings (e.g., Austin, 2012; Herbert, 2004; Herbert \& Trusty, 2006; McCarthy, 2013, 2016; Schultz et al., 2002; Thielsen \& Leahy, 2001). There have been few studies conducted to examine undergraduate supervisees' perspectives of effective practicum supervision. Rehabilitation educators and researchers are cognizant of and dutifully comply with the ethical principles of practices that prepare competent future rehabilitation professionals to serve people with disabilities (Herbert, 2004, 2006; Herbert et al., 2010). Given the significance of practicum site supervision experiences on career preparation for undergraduate students, it is important to examine how undergraduate students perceive their practicum site supervision experiences.

The purpose of the present study was to examine the effectiveness of undergraduate rehabilitation services practicum supervision. The study explored three research questions:

1. How satisfied are undergraduate rehabilitation services students with their practicum site supervision sessions?

2. What do undergraduate rehabilitation services students think of the competence level of their practicum site supervisors?

3. What factors are predictive of the perceived effectiveness of undergraduate rehabilitation services practicum supervision?

\section{Method}

\section{Participants}

The convenience sample consisted of 154 Hispanic undergraduate rehabilitation services students. The mean age of the participants was 23.65 years old $(S D=4.78)$, ranged from 19 to 52 years. Four participants did not disclose their age. Female students made up the majority of the sample $(n=126$, $81.8 \%$ ) while male students accounted for the remaining sample $(n=28,18.2 \%)$. In terms of class standing, all were seniors with the exception of four juniors $(2.6 \%)$. The most preferred practicum setting among the students was school $(n=68,44.2 \%)$ followed by other $(n=38,24.7 \%)$, vocational rehabilitation $(n=29,18.8 \%)$, alcohol/substance recovery $(n=10,6.5 \%)$, community mental health $(n=5,3.2 \%)$, and hospital $(n=4,2.6 \%)$. Most of the participants reported that they and their practicum supervisors were of the same race $(n=129,83.8 \%)$ while the remaining participants reported their practicum supervisors were of a different race $(n=25,16.2 \%)$. In addition, approximately $56.5 \%(n=87)$ of the students were supervised by a supervisor of the same sex and $43.5 \%(n=67)$ of them had a supervisor of the opposite sex. In regard to the frequency of supervision sessions, $133(86.4 \%)$ participants met with their practicum supervisors once a week, $16(10.4 \%)$ participants met once every other week, and $5(3.2 \%)$ participants met once a month. The average length of each supervision session lasted about 49.94 minutes.

\section{Measures}

The research team developed the demographic portion of the questionnaire, which was followed by The Supervision Outcome Questionnaire (SOQ: Worthington \& Roehlke, 1979). The SOQ consists of three separate single items that measure the following aspects of supervision: (1) satisfaction with supervision, (2) competence in supervisor, and (3) frequency of interactions between the supervisor and the supervisee. We used the first two statements for answering the first and second research questions, respectively. The third statement was used as a predictor variable in the multiple regression analysis model. Statement \#1 asks "How satisfied were you with your supervision sessions?" The item is scored on a seven-point Likert-type scale, ranging from $1=$ Totally unsatisfied to $7=$ Totally satisfied. The higher scores indicate greater levels of satisfaction with supervision. Statement \#2 asks "How competent your supervisor was at giving good supervision?" The item is scored on a seven-point Likerttype scale, ranging from $1=$ Totally incompetent to $7=$ Totally competent. The higher scores indicate greater levels of supervisor competency. Statement \#3 asks "How much interactions with your supervisor contributed to improvement in your counseling ability?" The item is scored on a seven-point Likert-type scale, ranging from $1=$ Had almost no effect to $7=$ Had a very large effect. The higher scores indicating more interactions with the supervisor led to more improvements in the student's counseling ability.

Next, the survey included The Working Alliance Inventory-Supervision Short Form (WAI-S: Ladany, Mori, \& Mehr, 2007). The WAI-S is a 12-item instrument that measures the perceived effectiveness of counselor supervision. Ladany et al. (2007) shortened the original 19-item student version of the Supervisory Working Alliance Inventory (Efstation, Patton, \& Kardash, 1990) by eliminating correlated items. Each item is scored on a seven-point Likert-type rating, ranging from $1=\mathrm{Never}$ to $7=$ Always. The total possible score ranges between 12 and 84, with higher scores indicating greater perceived supervision effectiveness. Item \#4 was reversely scored. An example statement includes "I am confident in my supervisor's ability to supervise me." For the present study, the Cronbach's $\alpha$ reliability coefficients of the WAI-S was computed to be .780 .

\section{Procedure}

Upon receipt of official approval for the study from the Institutional Review Board, the research team contacted all practicum instructors to obtain permission to visit their classes to administer paper-and-pencil questionnaires to the students. Research team members explained the purpose of the study and the rights the participants had. The questionnaire took approximately 15 minutes to complete. For the present study, 154 college students were recruited from a large, Hispanic-serving institution located in the southwestern region of the United States. The participants were rehabilitation services majors completing their first or second practicum. 


\section{Data Analysis}

Power analysis was conducted with seven predictor variables, using a power of .80 and an alpha level of .05 . G*Power suggested a sample size of 103 would be needed to detect a medium effect size, $f^{2}=.15$ (Cohen, 1988; Faul, Erdfelder, Buchner, \& Lang, 2009). To address the first and second research questions, we used descriptive statistics to find the frequency of distribution. To address the third research question, we used a multiple regression analysis. Skewness and kurtosis were used to check the normal distribution of all the variables separately. When both the skewness and kurtosis are close to zero, the bell-shape curve of a univariate should look symmetrical on both tails, indicating that there are no serious outliers (Gravetter, Wallnau, \& Forzano, 2018). We used the Mahalanobis distance to check for multivariate outliers. We also consulted the Table of Critical Values for chi-square and used the stringent level of $p=.001$. Because we had 7 degrees of freedom (i.e., 7 independent variables), any case with a squared Mahalanobis value that was equal to or greater than 24.322 was considered to be a multivariate outlier (Meyers, Gamst, \& Guarino, 2017). A bivariate correlation matrix was used to screen for multicollinearity and to ensure no correlation exceeded .70 (Warner, 2013). In addition, variance inflation factors (VIF) were scrutinized for each regression analysis to ensure there was no violation of the multicollinearity value that was greater than 5 (Tabachnick \& Fidell, 2013).

\section{Results}

Generally, the students were pleased with the supervision they received at the practicum sites. Close to two-thirds $(63 \%)$ of the participants reported being totally satisfied with their supervision sessions. More than one-quarter $(28.3 \%)$ of the participants indicated that they were mostly satisfied with the supervision sessions they received. Five participants (3.1\%) found their supervision sessions to be more satisfied than not. Seven participants $(4.4 \%)$ were neither satisfied nor unsatisfied with their supervision sessions. Two participants (1.3\%) indicated that they were totally unsatisfied with the supervision they received.

The second research question asked the students how competent they thought their supervisors were at giving good supervision. Generally, the students thought their practicum supervisors were quite competent in training them. One hundred and ten participants $(71.4 \%)$ rated their supervisors totally competent. Twenty-six participants $(16.9 \%)$ rated their supervisors mostly competent. Ten participants $(6.5 \%)$ rated their supervisors more competent than not. Six participants $(3.9 \%)$ rated their supervisors neither competent nor incompetent. One student $(0.6 \%)$ felt the supervisor was neither competent nor incompetent. Another student $(0.6 \%)$ indicated that the supervisor was totally incompetent.

We answered the third research question using multiple regression analysis with simultaneous entry of seven predictor variables. In this analysis, the criterion variable was the perceived effectiveness of practicum supervision, and the predictor variables included satisfaction with supervision, level of supervision competence, improvement in counseling ability, the frequency of supervision session, the length of supervision session, the supervisor and
TABLE 1. Multiple Regression Analysis for Predictors of Effectiveness of Practicum Supervision $(N=154)$

\begin{tabular}{|c|c|c|c|c|c|}
\hline Variable & $B$ & $S E B$ & $95 \% \mathrm{CI}(B)$ & $\beta$ & $t$ \\
\hline Constant & 32.531 & 4.799 & {$[23.047,42.015]$} & & 6.779 \\
\hline Satisfaction & 1.907 & 0.823 & {$[0.280,3.533]$} & $0.191 *$ & 2.317 \\
\hline Competency & 1.822 & 0.624 & {$[0.590,3.055]$} & $0.232 * *$ & 2.922 \\
\hline $\begin{array}{l}\text { Improvement in } \\
\text { counseling ability }\end{array}$ & 2.103 & 0.519 & {$[1.077,3.129]$} & $0.341 * * *$ & 4.051 \\
\hline $\begin{array}{l}\text { Frequency of } \\
\text { supervision } \\
\text { sessions }\end{array}$ & 0.909 & 0.967 & {$[-1.002,2.820]$} & 0.056 & 0.940 \\
\hline $\begin{array}{l}\text { Length of super- } \\
\text { vision sessions }\end{array}$ & 0.019 & 0.016 & {$[-0.011,0.050]$} & 0.078 & 1.242 \\
\hline Same-sex match & 0.769 & 0.914 & {$[-1.037,2.575]$} & 0.051 & 0.842 \\
\hline Same-race match & -1.896 & 1.189 & {$[-4.324,0.381]$} & -0.094 & -1.594 \\
\hline \multicolumn{6}{|c|}{$\begin{array}{l}F(7,146)=20.975, p<.001, R^{2}=.501, \text { Adjusted } R^{2}=.478 \\
\text { Note. } p^{* * *}<.001, p^{* *}<.01, p^{*}<.05\end{array}$} \\
\hline
\end{tabular}

supervisee were of same sex, and the supervisor and supervisee were of same race. Results of this regression are presented in Table 1. The regression model was statistically significant and the linear combination of predictor variables accounted for $50 \%$ of the variance explained in the perceived effectiveness of practicum supervision. Because the tendency of $R^{2}$ to overstate its estimation of the sample, we further computed the adjusted $R^{2}$ to be .478 , which qualifies to be a large effect (Cohen, 1988). Improvement in counseling ability was the strongest predictor in the regression model, $(p<.001)$, while the level of competence in the supervisor was the second-best predictor, $(p<.01)$, and satisfaction with supervision, $(p<.05)$, the third predictor. The squared semi-partial correlation for same sex showed that it accounted for almost no variance in the criterion variable. The squared semi-partial correlation for same race showed that it accounted for almost no variance in the criterion variable.

\section{Discussion}

The present study aimed to examine the perceived effectiveness of practicum supervision in Hispanic undergraduate rehabilitation services students. Our findings suggest that most of the students were quite satisfied with the practicum supervision sessions that they received. They also thought highly of their supervisors' ability in providing competent practicum supervision. Consistent with the findings of previous research (Ladany et al., 1999; Sterner, 2009), novice interns are usually eager and curious to learn useful, hands-on skills in working with actual clients from seasoned counselors and practitioners. As a result, they are more likely to report having had positive practicum experience when they gain new clinical knowledge outside of the classroom. Another plausible explanation for high levels of perceived supervisor competency is that many students chose a practicum site from a listing maintained by the department that rehabilitation services faculty members had carefully screened and knew the supervisors well in a professional capacity. Furthermore, through word-ofmouth students might choose or avoid an agency or clinic after 
inquiring as to the practicum experience of their classmates who had worked there.

Consistent with prior research (Cheon et al., 2008; Gatmon, et al., 2001, Jackson et al., 2003; Jordan, 2007), the current study demonstrated that supervisor-supervisee match on sex or race was not a significant indicator of trainees' satisfaction of supervision sessions. However, in terms of sex, older research yielded contrasting results. Worthington and Stern (1985) found that supervisees in sex-matched supervision perceived that relationship as closer than their peers who were not sex-matched with their supervisors. In addition, the sex-matched supervisees more often attributed their improvement to their supervisors than nonsex-matched supervisees. The different results could be due to an increased body of knowledge in the field of counselor education and supervision in terms of how to address and transcend sex differences in counselor supervision dyads (Doughty \& Leddick, 2007; Hindes \& Andrews, 2011; Rarick \& Ladany, 2013).

Interestingly, the frequency and length of supervision sessions were not significant indicators of supervisee satisfaction. Perceived competency of the supervisor and improvement in supervisee counseling ability were, however, found to be statistically significant. CACREP (2015) requires weekly one-hour supervision sessions that are individual or triadic, in addition to one-and-a-half hours of group supervision on a weekly basis. Participants of the current study reported varying amounts of supervision sessions, including consistently not meeting CACREP standards for supervision time. This could be the result of students underreporting sessions perhaps due to confusion about what constituted as formal supervision, or site supervisors being unable to meet the program's minimum required hours of supervision due to time constraints. Although the frequency and length of supervision sessions are mandated by CACREP for graduate students, quality, rather than amount, of supervision appears to be more important to supervisees given the statistical significance of perceived competency and improvement of counseling ability in the present study. This appears to buttress the assertions of past studies that a strong supervisory working alliance increases both supervisee satisfaction and client outcomes (Cheon, et al., 2008; Ladany, et al., 1999; McCarthy, 2013). Given the results of previous research and the current study, structuring sessions to include building a strong working alliance and increasing counselor competency skills would be helpful to raise supervisee satisfaction.

\section{Limitations}

First, the study was conducted in south Texas near the U.S.-Mexico border where $92 \%$ of the region's population are Hispanic or Latino (U.S. Census Bureau, 2017), and approximately $89 \%$ of the local university population are Hispanic or Latino (University of Texas Rio Grande Valley, 2017). The lack of racial/ethnic diversity of the population not only questions the generalizability of the study but may explain why race/ethnicity did not factor into student satisfaction of the supervisory relationship. Supervisor and supervisee cultures do not commonly tend to be different in this region thus may not demonstrate a significant statistical impact on satisfaction. Second, different training programs also may adopt different training methods. The specific pedagogy employed at this south Texas university studied may be markedly different from other institutions, which also affects the generalizability of this study. In addition, it is unknown if supervision sessions were conducted in individual, group, or a combination or formats. The specific method of supervision may impact student satisfaction, as the study did not take into account supervisee preferences.

\section{Implications}

Future research may take into account the limitations of this study to compare the effectiveness of different models of supervision. Specifically, comparisons may be made on the effectiveness of supervision based on different counseling theories. Researchers should also take care to operationalize what constitutes quality supervision. A qualitative study examining what supervisees thought especially helpful and not helpful about the supervision sessions they engaged in would be beneficial. For the rehabilitation services profession to remain relevant and viable in the everchanging allied health sphere, more studies are needed to improve and update the accreditation review process (Shaw \& Kuehn, 2009).

Given the results of the present study, both academic undergraduate rehabilitation faculty and site supervisors could focus on building strong working alliances with practicum students, as this seemed especially important in supervisee satisfaction. Increasing counselor competency skills in supervision also appears important. It is suggested that if there is a minimal amount of case material to discuss with supervisees due to low client workload, supervision time could be spent on discussing general counseling issues that supervisees are less confident about and teaching more advanced techniques and interventions to address those issues. Undergraduate program coordinators may consider taking the above issues into account when structuring their programs.

\section{References}

Austin, B. S. (2012). A qualitative analysis of vocational rehabilitation counselor perceptions of clinical supervision. Journal of Applied Rehabilitation Counseling, 43(3), 25-33.

Bailey, S. F., Barber, L. K., \& Nelson, V. L. (2017). Undergraduate internship supervision in psychology departments: Use of experiential learning best practices. Psychology Learning \& Teaching, 16(1), 74-83. doi: 10.1177/147572571 6671234

Bernard, J. M., \& Goodyear, R. K. (2014). Fundamentals of clinical supervision (5th ed.). Boston, MA: Pearson Publishing.

Blanton, P. G. (2001). A model for supervising undergraduate internships. Teaching of Psychology, 28(3), 217-219.

Bradley, C., \& Fiorini, J. (1999). Evaluation of counseling practicum: National study of programs accredited by CACREP. Counselor Education and Supervision, 39(2), 110-119. doi: 10.1002/j.1556-6978.1999.tb01222.x

Cashwell, T. H., \& Dooley, K. (2001). The impact of supervision on counselor self-efficacy. The Clinical Supervisor, 20(1), 39-47. doi: 10.1300/J001v20n01_03 
Cheon, H. S., Blumer, M. L., Shih, A. T., Murphy, M. J., \& Sato, M. (2009). The influence of supervisor and supervisee matching, role conflict, and supervisory relationship on supervisee satisfaction. Contemporary Family Therapy, 31(1), 52-67. doi: /10.1007/s10591-008-9078-y

Cohen, J. (1988). Statistical power analysis for the behavioral sciences (2nd ed.). Hillsdale, NJ: Erlbaum.

Council for Accreditation of Counseling and Related Educational Program (2015). 2016 CACREP standards. Retrieved from http:/www.cacrep.org/wp-content/uploads/2017/07/2016Standards-with-Glossary-7.2017.pdf

Council for Accreditation of Counseling and Related Educational Program (2017a). CACREP/CORE merger. Retrieved from https://www.cacrep.org/news-and-events/ cacrepcore-updates/

Council for Accreditation of Counseling and Related Educational Program(2017b). Registry of undergraduaterehabilitation programs. Retrieved from https://www.cacrep.org/ for-students/registry-of-undergraduate-rehabilitationprograms/

Council on Rehabilitation Education (2017). Standards for rehabilitation counselor education programs. Retrieved from http://www.cacrep.org/wp-content/uploads/2017/ 07/CORE-Standards-for-Rehabilitation-CounselorEducation-Programs.pdf

Crebert, G., Bates, M., Bell, B., Patrick, C. J., \& Cragnolini, V. (2004). Developing generic skills at university, during work placement and in employment: Graduates' perceptions. Higher Education Research \& Development, 23(2), $147-165$.

D’Abate, C. (2010). Developmental interactions for business students: Do they make a difference? Journal of Leadership \& Organizational Studies, 17(2), 143-155.

Daresh, J. C. (1990). Learning by doing: Research on the educational administration practicum. Journal of Educational Administration, 28(2), 34-47. doi: 10.1108/09578239010143468

Doughty, E. A., \& Leddick, G. R. (2007). Gender differences in the supervisory relationship. Journal of Professional Counseling: Practice, Theory, and Research, 35(2), 17-30.

Efstation, J. F., Patton, M. J., \& Kardash, C. M. (1990). Measuring the working alliance in counselor supervision. Journal of Counseling Psychology, 37(3), 322-329.

Faul, F., Erdfelder, E., Buchner, A., \& Lang, A. G. (2009). Statistical power analyses using $\mathrm{G}^{*}$ Power 3.1: Tests for correlation and regression analyses. Behavior Research Methods, 41(4), 1149-1160. doi: 10.3758/BRM.41.4.1149

Fernald, C. D., Tedeschi, R. G., Siegfried, W. D., Gilmore, D. C., Grimsley, D. L., \& Chipley, B. (1982). Designing and managing an undergraduate practicum course in psychology. Teaching of Psychology, 9(3), 155-160.

Gatmon, D., Jackson, D., Koshkarian, L., Martos-Perry, N., Molina, A., Patel, N., \& Rodolfa, E. (2001). Exploring ethnic, gender, and sexual orientation variables in supervision: Do they really matter? Journal of Multicultural Counseling and Development, 29(2), 102-113.

Glosoff, H. L., \& Matrone, K. F. (2010). Ethical issues in rehabilitation counselor supervision and the new 2010 code of ethics. Rehabilitation Counseling Bulletin, 53(4), 249-254.

Gravetter, F. J., \& Wallnau, L. B., \& Forzano, L. B. (2018). Essentials of statistics for the behavioral sciences (9th ed.). Belmont, CA: Wadsworth.

Herbert, J. T. (2004). Analysis of clinical supervision practices as documented in rehabilitation counseling syllabi and fieldwork manuals. Rehabilitation Education, 18(1), 13-33.

Herbert, J. T. (2006). Accreditation options for the undergraduate rehabilitation program. Rehabilitation Education, 20(3), 179-190.

Herbert, J. T., Barrett, K., Evenson, T., \& Jacob, C. J. (2010). Work roles and functions of undergraduate rehabilitation services alumni: A pilot study. Rehabilitation Education, 24(3\&4), 149-166.

Herbert, J. T., \& Trusty, J. (2006). Clinical supervision practices and satisfaction within the public vocational rehabilitation program. Rehabilitation Counseling Bulletin, 49(2), 66-80. doi: 10.1177/00343552060490020801

Hernandez, K. E., Bejarano, S., Reyes, F. J., Chavez, M., \& Mata, H. (2014). Experience preferred: Insights from our newest public health professionals on how internships/practicums promote career development. Health Promotion Practice, 15(1), 95-99. doi: 10.1177/1524839913507578

Hindes, Y. L., \& Andrews, J. W. (2011). Influence of gender on the supervisory relationship: A review of the empirical research from 1996 to 2010. Canadian Journal of Counseling \& Psychotherapy, 45(3), 240-261.

Jackson, V. A., Palepu, A., Szalacha, L., Caswell, C., Carr, P. L., \& Inui, T. (2003). "Having the Right Chemistry": A qualitative study of mentoring in academic medicine. Academic Medicine, 78(3), 328-334.

Jordan, K. (2007). Beginning supervisees' identity: The importance of relationship variables and experience versus gender matches in the supervisee/supervisor interplay. The Clinical Supervisor, 25(1-2), 43-51. doi: 10.1300/ J001v25n01_04

Jordan, K., \& Kelly, W. E. (2011). A preliminary factor analytic investigation of beginning counseling students worries. Psychology Journal, 8(1), 2-10.

Kuo, H. J., Connor, A., Landon, T. J., \& Chen, R. K. (2016). Managing anxiety in clinical supervision. Journal of Rehabilitation, 82(3), 18-27.

Ladany, N., Ellis, M. V., \& Friedlander, M. L. (1999). The supervisory working alliance, trainee self-efficacy, and satisfaction. Journal of Counseling \& Development, 77(4), 447-455.

Ladany, N., Mori, Y., \& Mehr, K. E. (2007). Trainee perceptions of effective and ineffective supervision interventions. Unpublished manuscript, Lehigh University, Bethlehem, Pennsylvania. 
Lynch, R. T. (1995). Supervision in rehabilitation counselling: Applications of theory to understand supervision style and the supervisory working alliance. Journal of Applied Rehabilitation Counseling, 26(2), 3-11.

McCarthy, A. K. (2013). Relationship between supervisory working alliance and client outcomes in state vocational rehabilitation counseling. Rehabilitation Counseling Bulletin, 57(1), 23-30. doi: 10.1177/0034355213484177

McCarthy, A. K. (2016). An Exploration of supervision styles within master's-level rehabilitation counseling internships. Journal of Applied Rehabilitation Counseling, 47(1), 17-23.

McElwee, C. N., O'reilly, P., \& McKenna, S. (2002). From moth to butterfly: Thoughts on student practica supervision from education and practice. Child and Youth Care Forum, 31(4), 269-281.

Mpofu, E. (2004). Teaching with service learning: Strategies and opportunities for rehabilitation counselor educators. Rehabilitation Education, 18(2), 121-132.

Meyers, L. S., Gamst, G., \& Guarino, A. J. (2017). Applied multivariate research: Design and interpretation (3rd ed.). Thousand Oaks, CA: SAGE Publications Ltd.

Pitt, J. S. (2009). Relationship between person-organization fit, job satisfaction, organizational commitment, and turnover intent among state vocational rehabilitation counselors. Unpublished doctoral dissertation, Michigan State University, East Lansing, Michigan.

Rarick, S., \& Ladany, N. (2013). The relationship of supervisor and trainee gender match and gender attitude match to supervisory style and the supervisory working alliance. Counseling and Psychotherapy Research, 13(2), 138-144.

Ryan, G., Toohey, S., \& Hughes, C. (1996). The purpose, value, and structure of the practicum in higher education: A literature review. Higher Education, 31(3), 355-377.

Schultz, J. C., Ososkie, J. N., Fried, J. H., Nelson, R. E., \& Bardos, A. N. (2002). Clinical supervision in public rehabilitation counseling settings. Rehabilitation Counseling Bulletin, 45(4), 213-222. doi: 10.1177/003435520204500404011

Shaw, L. R., \& Kuehn, M. D. (2009). Rehabilitation counselor education accreditation: History, structure, and evolution. Rehabilitation Counseling Bulletin, 52(2), 69-76.

Shoenfelt, E. L., Kottke, J. L., \& Stone, N. J. (2012). Master's and undergraduate industrial/organizational internships: Data-based recommendations for successful experiences. Teaching of Psychology, 39(2), 100-106. doi: $10.1177 / 0098628312437724$

Sterner, W. R. (2009). Influence of the supervisory working alliance on supervisee work satisfaction and work-related stress. Journal of Mental Health Counseling, 31(3), 249-263.

Tabachnick, B. G., \& Fidell, L. S. (2013). Using multivariate statistics (6th ed.). Boston, MA: Allyn \& Bacon.

Thielsen, V. A., \& Leahy, M. J. (2001). Essential knowledge and skills for effective clinical supervision in rehabilitation counseling. Rehabilitation Counseling Bulletin, 44(4), 196-208. doi: 10.1177/003435520104400402

Trepal, H. C., Bailie, J., \& Leeth, C. (2010). Critical incidents in practicum supervision: Supervisees' perspectives. Journal of Professional Counseling, Practice, Theory, \& Research, 38(1), 28-38.

United States Census Bureau. (2017). Quickfacts: Hidalgo County, Texas, United States. Retrieved from https://www.census. gov/quickfacts/fact/table/hidalgocountytexas,US/ PST045217

University of Texas Rio Grande Valley (2017). UTRGV enrollment profile fall 2017. Retrieved from http://www.utrgv. edu/sair/_files/documents/fall\%202017\%20student $\%$ 20profile.pdf

Warner, R. M. (2013). Applied statistics: From bivariate through multivariate techniques (2nd ed.). Thousand Oaks, CA: Sage.

Worthington Jr., E. L., \& Roehlke, H. J. (1979). Effective supervision as perceived by beginning counselors-in-training. Journal of Counseling Psychology, 26(1), 64-73. doi: 10.1037/0022-0167.26.1.64

Worthington Jr., E. L., \& Stern, A. (1985). Effects of supervisor and supervisee degree level and gender on the supervisory relationship. Journal of Counseling Psychology, 32(2), 252-262. doi: 10.1037/0022-0167.32.2.263

Roy K. Chen, PhD, CRC is a professor of rehabilitation counseling in the School of Rehabilitation Services and Counseling, the College of Health Professions at the University of Texas Rio Grande Valley.

Kim L. Nguyen-Finn, MA, LPC-S is a lecturer and doctoral candidate at the University of Texas Rio Grande Valley in the School of Rehabilitation Counseling and Services. She has been a mental health counselor since 1998 and is a Texas Licensed Professional Counselor Board-approved Supervisor.

Jinhee Park, PhD, CRC is an assistant professor in the Department of Special Education, Rehabilitation, and Counseling at Auburn University. Her research interests include psychiatric rehabilitation, working alliance between counselors and clients, vocational rehabilitation for transition youth with disabilities, multicultural learning environments, and multicultural issues among individuals with diverse cultural backgrounds. 